EXTENDED REPORT

\title{
Endothelial dysfunction in young patients with rheumatoid arthritis and low disease activity
}

\author{
G Vaudo, S Marchesi, R Gerli, R Allegrucci, A Giordano, D Siepi, M Pirro, Y Shoenfeld, G Schillaci, \\ E Mannarino
}

Ann Rheum Dis 2004;63:31-35. doi: 10.1136/ard.2003.007740

See end of article for authors' affiliations

Correspondence to: Dr G Vaudo, Unit of Internal Medicine, Angiology and

Arteriosclerosis

Department of Clinical and Experimental Medicine, University of Perugia

School of Medicine, via

Brunamonti, 51-06122

Perugia, Italy;

graudo@unipg.it

Accepted 12 May 2003
Background: Rheumatoid arthritis (RA) is associated with an increased risk of cardiovascular disease. Endothelial dysfunction represents the earliest stage of atherosclerosis.

Objective: To evaluate the influence of chronic inflammatory state on endothelial function in patients with RA by measuring endothelial reactivity in young patients with RA with low disease activity and without traditional cardiovascular risk factors.

Methods: Brachial flow mediated vasodilatation (FMV), assessed by non-invasive ultrasound, was evaluated in 32 young to middle aged patients with RA (age $\leqslant 59$ years), with DAS28 $\leqslant 3.2$ and without overt cardiovascular disease, and in 28 age and sex matched controls.

Results: Mean (SD) FMV was significantly lower in patients than in controls (3.2 (1.3)\% v 5.7 (2.0)\%; $\mathrm{p}<0.001)$, inversely related to low density lipoprotein cholesterol $(r=-0.45, p<0.05)$ and $C$ reactive protein (CRP), expressed as the value at the moment of ultrasound evaluation $(r=-0.44, p<0.05)$, as the average of CRP levels evaluated at different times during the disease $(r=-0.47, p<0.05)$, or as the average of $\geqslant 4$ determinations multiplied by the disease duration $(r=-0.40, p<0.05)$. In a multivariate regression model, a lower brachial flow mediated vasodilatation was independently predicted by low density lipoprotein cholesterol $(\beta=-0.40, p<0.05)$, average CRP levels multiplied by the disease duration $(\beta=-0.44, p<0.05)$, and brachial artery diameter $(\beta=-0.28, p<0.05)$.

Conclusions: Young to middle aged patients with RA with low disease activity, free from cardiovascular risk factors and overt cardiovascular disease, have an altered endothelial reactivity that seems to be primarily related to the disease associated chronic inflammatory condition.
$\mathrm{R}$ heumatoid arthritis (RA) is characterised by a high cardiovascular mortality, which exceeds that of the general population. ${ }^{1-4}$ About $50 \%$ of atherosclerotic coronary artery disease in the community occurs in the absence of "traditional" cardiovascular risk factors, including male sex, family history for cardiovascular disease, age, dyslipidaemia, arterial hypertension, diabetes mellitus, smoking, and obesity. ${ }^{5}$ Increasing evidence suggests a key role of inflammation in the onset and progression of atherosclerosis. ${ }^{6}$ Experimental studies have shown that several inflammatory mediators, including activated leucocytes, cytokines, and $\mathrm{C}$ reactive protein (CRP), have an active role within the atherosclerotic plaques. ${ }^{78}$ Moreover, some large scale prospective epidemiological studies have shown that high serum levels of inflammatory markers, such as CRP, are predictive of future cardiovascular events. ${ }^{9-12}$

Altered function of the arterial endothelium is currently considered the earliest stage of the development of the atheroma. Endothelial dysfunction is also recognised as a promoter of the disease progression and a trigger of cardiovascular events. It may be detected as an impaired ability of the artery to dilate in response to a variety of physical and chemical stimuli, as a consequence of a reduced nitric oxide bioavailability. ${ }^{13}$ Ultrasonographic determination of arterial vasodilatation after post-occlusion reactive hyperaemia (flow mediated vasodilatation (FMV)) is an accurate and reproducible non-invasive method for evaluating endothelial function in humans. ${ }^{14}$

Endothelial dysfunction has been recently described in patients with RA with high inflammatory activity, ${ }^{15-17}$ and an improvement in endothelial function has been observed after treatment with disease modifying antirheumatic drugs. ${ }^{15} 16$
Similar findings were reported after treatment of patients affected by primary systemic necrotising vasculitis. ${ }^{18}$ Although these findings support the notion that acute systemic inflammation favours altered endothelial reactivity, it is unknown whether a chronic inflammatory condition, such as RA, leads to the impairment of endothelial function, independently of disease flares.

This study aimed at evaluating the influence of chronic inflammatory state on endothelial function in patients with RA. For this purpose, brachial artery FMV was measured in young patients with RA with low disease activity and without conventional cardiovascular risk factors.

\section{METHODS}

Thirty two consecutive young patients (four men, 28 women; aged $\leqslant 59$ years, mean age 50 (7) years, range 27-59) meeting the American College of Rheumatology criteria for classification of RA. ${ }^{19}$ were enrolled from our outpatient clinic. The mean (SD) disease duration was 11 (8) years. Twenty eight subjects matched for age and sex acted as controls: 8 with fibromyalgia, 10 with knee osteoarthritis, and 10 with hand osteoarthritis.

All subjects underwent a detailed clinical global examination that also included measurement of height and weight. Disease activity was measured by the Disease Activity Score (DAS28), a validated score including tender and swollen joint count, erythrocyte sedimentation rate, and a patient global

Abbreviations: CRP, $\mathrm{C}$ reactive protein; DAS, Disease Activity Score; FMV, flow mediated vasodilatation; HDL, high density lipoprotein; LDL, low density lipoprotein; RA, rheumatoid arthritis; RF, rheumatoid factor 
assessment of disease activity. ${ }^{20}$ Only patients with low disease activity (DAS28 $\leqslant 3.2$ ) were enrolled into the study. In addition, patients and controls were excluded if they had a family history of premature ( $<55$ years in men, $<65$ years in women) coronary artery disease in a first degree relative, or if they were smokers or had stopped smoking for less than two years. We also excluded subjects with hypertension (defined by blood pressure $\geqslant 150 / 90 \mathrm{~mm} \mathrm{Hg}$ or using antihypertensive drugs), diabetes mellitus (defined according to the World Health Organisation criteria), ${ }^{21}$ history of hyperlipidaemia or obesity (body mass index $<30 \mathrm{~kg} / \mathrm{m}^{2}$ ), angina, previous myocardial infarction or stroke, active infectious diseases, kidney failure, neoplasms, or other connective tissue diseases.

In all subjects, blood was drawn in the morning after 13 hours' fasting, and the following variables were determined: erythrocyte sedimentation rate, rheumatoid factor (RF), and CRP (laser nephelometry), total cholesterol, triglycerides (enzymatic colorimetric method), high density lipoprotein (HDL) cholesterol (enzymatic colorimetric method after precipitation to polyethylene glycol), low density lipoprotein (LDL) cholesterol (Friedewald formula), and homocysteine (high performance liquid chromatography). Serum CRP concentration was determined as the level at the moment of the ultrasound examination (actual CRP). Then, to quantify the degree of inflammation over time in each patient, the average of CRP levels evaluated at different times during the disease (at least four determinations/year) was determined (average CRP) and this value was multiplied by the disease duration in years (CRP duration). All subjects were classified as RF+ or RF- on the basis of the presence or absence of RF in the serum, respectively. Twenty of the patients were receiving methotrexate ( $\leqslant 15 \mathrm{mg} /$ week) plus regular folic acid supplementation of $7.5 \mathrm{mg} /$ week, 13 were being treated with prednisone $(\leqslant 5 \mathrm{mg} /$ day), 6 with hydroxychloroquine $(200 \mathrm{mg} /$ day $), 2$ with azathioprine $(100 \mathrm{mg} /$ day $)$, and 2 with sulfasalazine $(2 \mathrm{~g} /$ day $)$. Nonsteroidal anti-inflammatory drugs, including cyclo-oxygenase- 2 inhibitors, were discontinued in all patients at least 30 days before vascular examination. The study protocol was approved by the ethical committee of our institution, and written consent was obtained from all subjects included in the study.

FMV was assessed on the brachial artery by ultrasonography. Any drug known to affect endothelial function, including nitrates, hypolipidaemic drugs, and aspirin, was withdrawn $\geqslant 1$ week before the examination. Details of the procedure, which was performed according to the International Brachial Artery Reactivity Task Force guidelines, ${ }^{14}$ have been reported elsewhere. ${ }^{22}$ Briefly, the measurements were performed in supine position on the non-dominant arm, after 10-20 minutes' resting in a quiet, dark room with a temperature of $22^{\circ} \mathrm{C}$. The brachial artery was scanned longitudinally just above the antecubital crease using a $10 \mathrm{MHz}$ probe (HDI 3500, Advanced Technology Laboratories). The diameter of the brachial artery was measured at the $\mathrm{R}$ wave of the electrocardiogram, on the interface between the media and adventitia of the anterior and posterior wall. Gain settings were optimised to identify the lumen and the vessel wall interfaces, and were not modified during the examination. Hyperaemia was induced by inflation of a pneumatic cuff ( $12.5 \mathrm{~cm}$ wide) at $230-250 \mathrm{~mm} \mathrm{Hg}$ for four minutes on the most proximal portion of the upper arm. The arterial diameter measurement was repeated 45-60 seconds after sudden deflation of the cuff. Tracings were recorded on videotape and read by one investigator, who was unaware of the subject's clinical data and temporal sequence. The average of three measurements of basal and post-hyperaemia diameter was used for the analysis. FMV was expressed as the relative increase in brachial artery diameter during hyperaemia, and defined as $100 \times($ (post-hyperaemia diameter-basal diameter)/basal diameter). Blood flow was measured as arterial cross sectional area $\left(\pi \times r^{2}\right)$ times mean Doppler velocity corrected for angle. The intraobserver between-occasion reproducibility of FMV in our laboratory was assessed in 10 subjects examined two days apart. The mean (SD) difference between the two examinations was $1.0(1.5) \%$.

\section{Statistical analysis}

Data are presented as mean (SD), and as median and interquartile range for CRP. Because CRP showed a nonGaussian distribution with a significant positive skewness, data are presented after logarithmic transformation. Student's $t$ test was performed to compare parametric variables between cases and controls. Pearson's correlation coefficient was used to examine the relation between brachial FMV and several study variables. Multiple linear regression analysis was performed with brachial FMV as dependent variable. The independent variables in the model were age, CRP duration after logarithmic transformation, triglycerides, HDL cholesterol, LDL cholesterol, systolic blood pressure, and brachial artery diameter. Levels of $\mathrm{p}<0.05$ were considered significant. Data were stored by SPSS statistical package, release 10.0 (SPSS Inc, Chicago, Illinois, USA).

\section{RESULTS}

Table 1 shows the characteristics of the study group. Patients with RA had significantly higher erythrocyte sedimentation rate $(26(15) \vee 11(5) \mathrm{mm} / \mathrm{lst} \mathrm{h} ; \mathrm{p}<0.001)$, actual CRP (12 (12) $v 2$ (12) mg/l; p<0.001), and average CRP levels (12 (9) $v 2$ (1) $\mathrm{mg} / \mathrm{l} ; \mathrm{p}<0.001)$ than controls. HDL cholesterol was higher in the total patient group than in controls (1.6 (0.5) $v$ $1.3(0.4) \mathrm{mmol} / \mathrm{l} ; \mathrm{p}<0.05)$, as well as in the two subsets of 13 subjects treated with steroids $(1.7(0.6) \mathrm{mmol} / \mathrm{l} ; \mathrm{p}<0.05)$ and 19 not treated with steroids ( $1.5(0.7) \mathrm{mmol} / \mathrm{l} ; \mathrm{p}<0.05)$. Table 2 shows that the FMV of the brachial artery was significantly lower in patients than in control subjects $(3.2$ (1.3) $v 5.7(2.0) \%$; $<0.001)$. A similar reduction of FMV was seen when the ultrasound examination was repeated in eight patients with stable disease activity after 30 and 60 days from

Table 1 Selected clinical characteristics of 32 patients with RA and 28 healthy control subjects

\begin{tabular}{|c|c|c|c|}
\hline Data & $\begin{array}{l}\text { Rheumatoid } \\
\text { arthritis } \\
(n=32)\end{array}$ & $\begin{array}{l}\text { Control } \\
\text { subjects } \\
\text { ( } n=28 \text { ) }\end{array}$ & $p$ Value \\
\hline Age (years) & 50 (7) & $48(8)$ & NS \\
\hline Men (\%) & 13 & 16 & NS \\
\hline Body mass index $\left(\mathrm{kg} / \mathrm{m}^{2}\right)$ & $23(2)$ & $22(2)$ & NS \\
\hline $\begin{array}{l}\text { Erythrocyte sedimentation rate } \\
(\mathrm{mm} / 1 \mathrm{st} \mathrm{h})\end{array}$ & $26(15)$ & $11(5)$ & $<0.001$ \\
\hline Systolic blood pressure $(\mathrm{mm} \mathrm{Hg})$ & $131(14)$ & $137(12)$ & NS \\
\hline Diastolic blood pressure $(\mathrm{mm} \mathrm{Hg})$ & $72(6)$ & $71(5)$ & NS \\
\hline Actual CRP (mg/l) & $10.4(5-18)$ & $2(1-6)$ & $<0.001$ \\
\hline Average CRP (mg/l) & $14(9-23)$ & $2(1-7)$ & $<0.001$ \\
\hline CRP duration (mg/l xyears) & $112(50-299)$ & - & - \\
\hline Rheumatoid factor positive (\%) & 53 & - & - \\
\hline Bone erosions (\%) & 49 & - & - \\
\hline Total cholesterol (mmol/l) & $5.7(0.9)$ & $5.1(1.1)$ & $<0.05$ \\
\hline LDL cholesterol (mmol/I) & $3.5(0.8)$ & $3.2(1.0)$ & NS \\
\hline HDL cholesterol (mmol/l) & $1.6(0.5)$ & $1.3(0.4)$ & $<0.05$ \\
\hline Triglycerides (mmol/l) & $1.0(0.7)$ & $1.3(0.6)$ & NS \\
\hline Homocysteine $(\mu \mathrm{mol} / \mathrm{l})$ & $5.9(1.6)$ & $6.8(2.8)$ & NS \\
\hline
\end{tabular}

Mean (SD) and median (interquartile range).

$\mathrm{CRP}, \mathrm{C}$ reactive protein; actual CRP, CRP at the moment of ultrasound examination; average CRP, CRP levels evaluated at different times during the disease (at least four determinations/year); CRP duration, average CRP multiplied by the duration of the disease in years. 
Table 2 Vascular parameters of the study group

\begin{tabular}{|c|c|c|c|}
\hline Parameter & $\begin{array}{l}\text { Rheumatoid } \\
\text { arthritis } \\
(n=32)\end{array}$ & $\begin{array}{l}\text { Control } \\
\text { subjects } \\
(n=28)\end{array}$ & p Value \\
\hline $\begin{array}{l}\text { Flow mediated vasodilatation } \\
\text { (\%) }\end{array}$ & $3.2(1.3)$ & $5.7(2.0)$ & $<0.001$ \\
\hline Brachial artery diameter $(\mathrm{mm})$ & $3.9(0.6)$ & $3.8(0.5)$ & NS \\
\hline Basal brachial flow (ml/min) & $120(22)$ & $133(38)$ & NS \\
\hline Post-hyperaemic flow $(\mathrm{ml} / \mathrm{min})$ & ) 290 (27) & $301(33)$ & NS \\
\hline \multicolumn{4}{|c|}{$\begin{array}{l}\text { Flow mediated vasodilatation, } 100 \times(\text { post-hyperaemia diameter-basa } \\
\text { diameter)/basal diameter); brachial artery diameter, diameter of the } \\
\text { brachial artery at the } \mathrm{R} \text { wave of the electrocardiogram; basal brachial } \\
\text { flow, basal arterial cross sectional area }\left(\pi \times \mathrm{r}^{2}\right) \text { times mean Doppler } \\
\text { velocity corrected for angle; post-hyperaemic flow, post-hyperaemic } \\
\text { arterial cross sectional area }\left(\pi \times \mathrm{r}^{2}\right) \text { times mean Doppler velocity correctec } \\
\text { for angle. }\end{array}$} \\
\hline
\end{tabular}

the first evaluation (time 0: $3.4(1.1) \%$, time $30: 3.3(1.4) \%$, time 60: $3.2(1.0) \% ; p=N S)$. No significant difference in brachial artery FMV was seen between patients without and with serum RF (3.5 (0.4) v 3.7 (0.9)\%, respectively; p= NS), and with or without bone erosions (3.7 (0.3) $v 3.6(0.7) \%$, respectively; $\mathrm{p}=\mathrm{NS}$ ).

At the univariate analysis (table 3), the baseline value of FMV showed an inverse correlation with LDL cholesterol $(r=-0.45, \mathrm{p}<0.05)$, actual CRP $(r=-0.44 ; \mathrm{p}<0.05)$, average CRP $(r=-0.47, \mathrm{p}<0.05)$, and CRP duration $(r=-0.48$, $\mathrm{p}<0.05$; fig 1 ). We did not find any significant correlation of FMV with age, HDL cholesterol, triglycerides, homocysteine, erythrocyte sedimentation rate, duration of disease, and systolic and diastolic blood pressure.

Table 4 shows the results of the multivariate linear regression analysis in patients with RA. A lower brachial artery FMV was independently predicted by LDL cholesterol $(\beta=-0.40, p<0.05)$, CRP duration $(\beta=-0.44, p<0.05)$, and brachial artery diameter $(\beta=-0.28, p<0.05)$. The multivariate model explained $50 \%$ of the observed variability of brachial artery FMV.

\section{DISCUSSION}

The present study shows that young to middle aged patients with RA with low disease activity without clinically overt atherosclerotic disease or traditional cardiovascular risk factors have an altered pattern of brachial FMV. Endothelial dysfunction was related to serum CRP values, measured both at the moment of the study and as the

Table 3 Univariate correlations of flow mediated vasodilatation with selected variables in patients with RA

\begin{tabular}{lrl} 
& \multicolumn{1}{l}{$\mathbf{R}$} & $\mathbf{p}$ \\
\hline Age & 0.22 & NS \\
LDL cholesterol & -0.45 & $<0.001$ \\
HDL cholesterol & -0.11 & $\mathrm{NS}$ \\
Triglycerides & 0.09 & $\mathrm{NS}$ \\
Homocysteine & 0.22 & $\mathrm{NS}$ \\
Erythrocyte sedimentation rate & 0.01 & $\mathrm{NS}$ \\
Actual CRP & -0.44 & $<0.001$ \\
Average CRP & -0.47 & $<0.001$ \\
CRP duration & -0.48 & $<0.001$ \\
Systolic blood pressure & 0.21 & $\mathrm{NS}$ \\
Diastolic blood pressure & 0.12 & $\mathrm{NS}$ \\
Disease activity score & 0.24 & $\mathrm{NS}$ \\
Disease duration & -0.29 & $\mathrm{NS}$
\end{tabular}

CRP, C reactive protein; DAS, Disease Activity Score; actual CRP, CRP at the moment of ultrasound examination; average CRP, the average of CRP levels evaluated at different times during the disease (at least four determinations/year); CRP duration, average CRP multiplied by the disease duration in years.

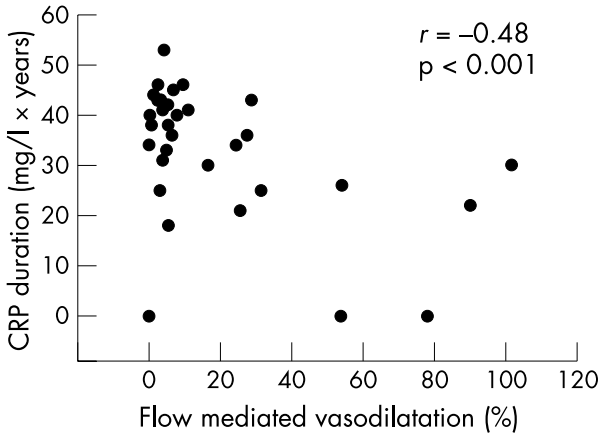

Figure 1 Univariate correlation between brachial artery flow mediated vasodilatation and CRP duration, expressed as average CRP in the past year multiplied by the disease duration in years.

Table 4 Independent predictors of brachial artery flow mediated vasodilatation in patients with RA

\begin{tabular}{llll}
\hline Predictor & $\boldsymbol{\beta}$ & $R^{2}$ & $\mathbf{P}$ \\
\hline Brachial artery diameter & -0.28 & 0.22 & $<0.01$ \\
CRP duration & -0.44 & 0.37 & $<0.01$ \\
LDL cholesterol & -0.40 & 0.50 & $<0.01$ \\
\hline
\end{tabular}

CRP duration, average CRP multiplied by the disease duration in years.

average of several previous determinations. Interestingly, the average CRP level multiplied by the disease duration, a marker of the degree of inflammation over the time, was the only predictor of impaired FMV in our patients, along with LDL cholesterol.

A number of data are available about the association between connective tissue diseases and arterial endothelial function. Experimental data suggest that acute inflammation may interfere with endothelial function ${ }^{23}$ through the action of proinflammatory cytokines which can modify the vascular release of both nitric oxide ${ }^{24}$ and endothelium derived hyperpolarising factor. ${ }^{25}$ An impaired endothelial reactivity has been shown in patients with systemic lupus erythematosus, ${ }^{26}$ necrotising vasculitis, ${ }^{18}{ }^{27}$ and Kawasaki disease. ${ }^{28}$ An altered endothelial function has been observed in some, ${ }^{16}{ }^{17}$ but not all, ${ }^{15}$ studies investigating patients with high activity RA. One of those reports found an impaired large- and smallartery compliance in a small group of patients with RA. ${ }^{15}$ Because arterial compliance is the result of an involvement of the arterial media layer, a combined endothelium and smooth muscle cell damage rather than an isolated endothelial injury can be proposed. ${ }^{15}$ Moreover, there is initial evidence that a decrease in disease activity induced by treatment is associated with an improvement of endothelial function. ${ }^{16}{ }^{17}$ These data and our own findings support the view that inflammation may have an influence on endothelial function in RA.

These data are of particular interest from a clinical point of view. Endothelial dysfunction is the earliest stage of atherosclerotic disease and the expression of a systemic phenomenon. Endothelial reactivity of the brachial artery shows a close correlation with that seen in the coronary arteries. ${ }^{29}$ Moreover, endothelial dysfunction at both the coronary $^{30}$ and peripheral ${ }^{31}$ level is a predictor of future cardiovascular events. Our observations, therefore, provide a basis for the observed epidemiological link between RA and atherosclerotic disease. ${ }^{1-4}$

The mechanisms underlying subclinical atherosclerotic disease in RA remain largely unknown. Firstly, a high prevalence of smokers has been reported in patients with RA. ${ }^{32}$ For this reason, smoking subjects were not included in 
our study to avoid confounding factors. Secondly, subjects affected by immunological disorders, including RA and systemic lupus erythematosus, are often characterised by increased levels of homocysteine, an emerging risk factor for cardiovascular diseases. ${ }^{33-35}$ In RA, raised serum homocysteine levels may be due, at least in part, to methotrexate. ${ }^{36}{ }^{37}$ Homocysteine levels in our patients with RA, however, did not differ from those of control subjects, and were not predictive of abnormal FMV. Finally, RA is associated with the evidence of an atherogenic lipid profile with LDL lipoprotein cholesterol concentration, ${ }^{38}$ and increased levels of LDL cholesterol ${ }^{39}$ and LP(a) lipoprotein, ${ }^{40}$ a lipoprotein with prothrombotic action. In our study, patients with RA had higher values of total cholesterol but also of HDL cholesterol than controls. This may be partially explained by corticosteroid treatment, which has been associated with an increase in HDL cholesterol concentrations. ${ }^{41}$ However, the fact that in our series HDL levels in the 19 patients not treated with steroids were significantly higher than those in controls and only slightly lower than, but not significantly different from, the levels of the 13 steroid treated subjects suggests that other factors may also be implicated in this enhancement.

In this study endothelial dysfunction in RA was related not only to LDL cholesterol levels but also to the inflammatory state. LDL cholesterol is an established risk factor for atherosclerosis in the general population, and its adverse prognostic significance may in part be related to its ability to induce endothelial dysfunction. ${ }^{42-44}$ Of note, the inflammatory microenvironment promotes the formation of oxidised LDLs which are responsible for oxidative injury of vascular wall. $^{5}$

This study supports the importance of inflammation as a determinant of endothelial dysfunction. This is in agreement with an increasing body of evidence suggesting that atherosclerosis may be considered a chronic inflammatory disorder. ${ }^{5}$ Indeed, large amounts of activated inflammatory cells, including monocytes, macrophages, and T lymphocytes, as well as increased expression of leucocyte adhesion molecules, have been documented in atherosclerotic plaques. ${ }^{5}$ Thus the present observation that the mean CRP level over time is a good predictor of impaired FMV in RA is a valuable finding from a pathogenetic and clinical point of view. CRP, indeed, is a predictor of future myocardial infarction and ischaemic stroke in the general population, even within its normal distribution range. ${ }^{9-11}$ In RA, cytokines such as interleukin 6 and tumour necrosis factor $\alpha$ modulate the hepatic synthesis of CRP. ${ }^{45-47}$ At the same time, CRP induces expression on the endothelial surface of adhesion molecules, including vascular cell adhesion molecule-1, intercellular adhesion molecule- 1 , and E-selectin, and promotes the adherence of leucocytes with the consequent initiation of vascular atherosclerotic damage. ${ }^{46}$

In conclusion, this study demonstrated that young to middle aged patients with RA with low disease activity, free from cardiovascular risk factors and overt cardiovascular disease, have an altered endothelial reactivity, which indicates a higher susceptibility to the development of atherosclerotic disease. Although confirming that traditional risk factors, such as LDL cholesterol, may be of importance in determining preclinical atherosclerotic damage in these patients, our results underline the pivotal role of the prolonged inflammatory state as a promoter of cardiovascular disease in RA.

\section{Authors' affiliations}

G Vaudo, S Marchesi, D Siepi, M Pirro, G Schillaci, E Mannarino, Internal Medicine, Angiology and Arteriosclerosis, University of Perugia School of Medicine, Perugia, Italy
R Gerli, R Allegrucci, A Giordano, Internal Medicine and Oncological Sciences, University of Perugia School of Medicine, Perugia, Italy Y Shoenfeld, Department of Medicine B, and Centre for Autoimmune Diseases, Chaim Sheba Medical Centre, Tel-Hashomer, Israel

\section{REFERENCES}

1 Wolfe F, Mitchell DM, Sibley JT, Fries JF, Bloch DA, Williams CA, et al. The mortality of rheumatoid arthritis. Arthritis Rheum 1994;37:481-94.

2 Krause D, Schleusser B, Herborn G, Rau R. Response to methotrexate treatment is associated with reduced mortality in patients with severe rheumatoid arthritis. Arthritis Rheum 2000:43:14-21.

3 Manzi S, Waasko MC. Inflammation-mediated rheumatic diseases and atherosclerosis. Ann Rheum Dis 2000;59:321-5.

4 Solomon DH, Karlson EW, Rimm EB, Cannuscio CC, Mandl LA, Manson JE, et al. Cardiovascular morbidity and mortality in women diagnosed with rheumatoid arthritis. Circulation 2003;107:1297-301.

5 Ross R. The pathogenesis of atherosclerosis: a perspective for the 1990s. Nature 1993;362:801-9.

6 Danesh J, Whincup P, Walker M, Lennon L, Thomson A, Appleby P, et al. Low grade inflammation and coronary heart disease: prospective study and updated meta-analyses. BMJ 2000;321:199-204.

7 Urieli-Shoval S, Linke RP, Matzner Y. Expression and function of serum amyloid A, a major acute-phase protein, in normal and disease states. Curr Opin Hematol 2000;7:64-9.

8 Yasojima K, Schwab C, McGeer EG, McGeer PL. Generation of C-reactive protein and complement components in atherosclerotic plaques. Am J Pathol 2001; 158:1039-51.

9 Ridker PM, Cushman M, Stampfer MJ, Tracy RP, Hennekens CH. Inflammation, aspirin, and the risk of cardiovascular disease in apparently healthy men. N Engl'J Med 1997;336:973-9.

10 Ridker PM, Buring JE, Shih J, Matias M, Hennekens CH. Prospective study of $\mathrm{C}$-reactive protein and the risk of future cardiovascular events among apparently healthy women. Circulation 1998;98:731-3.

11 Ridker PM, Hennekens CH, Buring JE, Rifai N. C-reactive protein and other markers of inflammation in the prediction of cardiovascular disease in women. N Engl J Med 2000;342:836-43.

12 Pirro M, Bergeron J, Dagenais GR, Bernard PM, Cantin B, Despres JP, et al. Age and duration of follow-up as modulators of the risk for ischemic heart disease associated with high plasma C-reactive protein levels in men. Arch Intern Med 2001;161:2474-80.

13 Celermajer DS, Sorensen KE, Gooch VM, Spiegelhalter DJ, Miller OI, Sullivan ID, et al. Non-invasive detection of endothelial dysfunction in children and adults at risk of atherosclerosis. Lancet 1992;340:1111-15.

14 Corretti MC, Anderson TJ, Benjamin EJ, Celermajer D, Charbonneau F, Creager MA, et al. Guidelines for the ultrasound assessment of endothelialdependent flow-mediated vasodilation of the brachial artery: a report of the International Brachial Artery Reactivity Task Force. J Am Coll Cardiol 2002;39:257-65.

15 Van Doornum S, McColl G, Jenkins A, Green DJ, Wicks IP. Screening for atherosclerosis in patients with rheumatoid arthritis: comparison of two in vivo tests of vascular function. Arthritis Rheum 2003;48:72-80.

16 Bergholm R, Leirisalo-Repo M, Vehkavaara S, Makimattila S, Taskinen MR, Yki-Jarvinen $\mathrm{H}$. Impaired responsiveness to $\mathrm{NO}$ in newly diagnosed patients with rheumatoid arthritis. Arterioscler Thromb Vasc Bio 2002;22:1637-41.

17 Hürlimann D, Forster A, Noll G, Enseleit F, Chenevard R, Distler O, et al. Antitumor necrosis factor-alpha treatment improves endothelial function in patients with rheumatoid arthritis. Circulation 2002;106:2184-7.

18 Raza K, Thambyrajah J, Townend JN, Exley AR, Hortas C, Filer A, et al. Suppression of inflammation in primary systemic vasculitis restores vascular endothelial function: lessons for atherosclerotic disease? Circulation 2000;102:1470-2

19 Arnett FC, Edworthy SM, Bloch DA, McShane DJ, Fries JF, Cooper NS, et al. The American Rheumatism Association 1987 revised criteria for the classification of rheumatoid arthritis. Arthritis Rheum 1988;31:315-24.

20 Prevoo ML, van't Hof MA, Kuper HH, van Leeuwen MA, van de Putte $L B$, van Riel PL. Modified disease activity scores that include twenty-eight-joint counts. Development and validation in a prospective longitudinal study of patients with rheumatoid arthritis. Arthritis Rheum 1995;38:44-8

21 World Health Organization Study Group on Diabetes Mellitus. Report of a WHO Study Group. Geneva: World Health Organization, 1985.

22 Marchesi S, Lupattelli G, Schillaci G, Pirro M, Siepi D, Roscini AR, et al. Impaired flow-mediated vasoactivity during post-prandial phase in young healthy men. Atherosclerosis 2000;153:397-402.

23 Hingorani AD, Cross J, Kharbanda RK, Mullen MJ, Bhagat K, Taylor M, et al. Acute systemic inflammation impairs endothelium-dependent dilatation in humans. Circulation 2000;102:994-9.

24 Yoshizumi M, Perrella MA, Burnett JC Jr, Lee ME. Tumor necrosis factor downregulates an endothelial nitric oxide synthase mRNA by shortening its half-life Circ Res 1993:73:205-9.

25 Kessler P, Popp R, Busse R, Schini-Kerth VB. Proinflammatory mediators chronically downregulate the formation of the endothelium-derived hyperpolarizing factor in arteries via a nitric oxide/cyclic GMP-dependent mechanism. Circulation 1999:99:1878-84.

26 Lima DSN, Sato El, Lima VC, Miranda F Jr, Hatta FH. Brachial endothelial function is impaired in patients with systemic lupus erythematosus. J Rheumatol 2002;29:292-7.

27 Filer AD, Gardner-Medwin JM, Thambyrajah J, Raza K, Carruthers DM Stevens RJ, et al. Diffuse endothelial dysfunction is common to ANCA 
associated systemic vasculitis and polyarteritis nodosa. Ann Rheum Dis 2003;62:162-7.

28 Dhillon R, Clarkson P, Donald AE, Powe AJ, Nash M, Novelli V, et al. Endothelial dysfunction late after Kawasaki disease. Circulation 1996:94:2103-6.

29 Anderson TJ, Uehata A, Gerhard MD, Meredith IT, Knab S, Delagrange D, et al. Close relation of endothelial function in the human coronary and peripheral circulations. J Am Coll Cardiol 1995;26:1235-41.

30 Schächinger V, Britten MB, Zeiher AM. Prognostic impact of coronary vasodilator dysfunction on adverse long-term outcome of coronary heart disease. Circulation 2000;101:1899-906.

31 Perticone F, Ceravolo R, Pujia A, Ventura G, lacopino S, Scozzafava A, et al. Prognostic significance of endothelial dysfunction in hypertensive patients. Circulation 2001;104:191-6.

32 Tuomi T, Heliovaara M, Palosuo T, Aho K. Smoking, lung function and rheumatoid factors. Ann Rheum Dis 1990;49:753-6.

33 Roubenoff R, Dellaripa P, Nadeau MR, Abad LW, Muldoon BA, Selhub J, et al. Abnormal homocysteine metabolism in rheumatoid arthritis. Arthritis Rheum 1997;40:718-22.

34 Petri M, Roubenoff R, Dallal GE, Nadeau MR, Selhub J, Rosenberg IH. Plasma homocysteine as a risk factor for atherothrombotic events in systemic lupus erythematosus. Lancet 1996;348:1120-4.

35 Clarke R, Daly L, Robinson K, Naughten E, Cahalane S, Fowler B, et al. Hyperhomocysteinemia: an independent risk factor for vascular disease. N Engl J Med 1991;324:1149-55.

36 Morgan SL, Baggott JE, Lee JY, Alarcon GS. Folic acid supplementation prevents deficient blood folate levels and hyperhomocysteinemia during longterm, low dose methotrexate therapy for rheumatoid arthritis: implications for cardiovascular disease prevention. J Rheumatol 1998;25:441-6.

37 Haagsma CJ, Blom HJ, van Riel PL, van't Hof MA, Giesendorf BA, van Oppenraaij-Emmerzaal D, et al. Influence of sulphasalazine, methotrexate, and the combination of both on plasma homocysteine concentrations in patients with rheumatoid arthritis. Ann Rheum Dis 1999;58:79-84.

38 Lakatos J, Harsagyi A. Serum total, HDL, LDL cholesterol, and triglyceride levels in patient with rheumatoid arthritis. Clin Biochem 1988;21:93-6.

39 Svenson KL, Lithell H, Hallgren R, Selinus I, Vessby B. Serum lipoprotein in active rheumatoid arthritis and other chronic inflammatory arthritides. I. Relativity to inflammatory activity. Arch Intern Med 1987;147:1912-16.

40 Rantapaa-Dahlqvist S, Wallberg-Johnsson S, Dahlen G. Lipoprotein (a), lipids, and lipoproteins in patients with rheumatoid arthritis. Ann Rheum Dis 1991; $50: 366-8$

41 Svenson KL, Lithell H, Hallgren R, Vessby B. Serum lipoprotein in active rheumatoid arthritis and other chronic inflammatory arthritides. II. Effects of anti-inflammatory and disease-modifying drug treatment. Arch Intern Med 1987; 147:1917-20.

42 The Lipid Research Clinics Coronary Primary Prevention Trial results. II: The relationship of reduction in incidence of coronary heart disease to cholesterol lowering. JAMA 1984;251:365-74.

43 Scandinavian Simvastatin Survival Study Group. Randomised trial of cholesterol lowering in 4444 patients with coronary heart disease: the Scandinavian Simvastatin Survival Study (4S). Lancet 1994;344:1383-9.

44 Chowienczyk PJ, Watts GF, Cockcroft JR, Ritter JM. Impaired endotheliumdependent vasodilation of forearm resistance vessels in hypercholesterolemia. Lancet 1992;340:1430-2.

45 Bacon PA, Raza K, Banks MJ, Townend J, Kitas GD. The role of endothelial cell dysfunction in the cardiovascular mortality of RA. Int Rev Immunol 2002; 21:1-17.

46 Pasceri V, Willerson JT, Yeh ET. Direct proinflammatory effect of C-reactive protein on human endothelial cells. Circulation 2000;102:2165-8.

47 Molenaar ETH, Voskuyl AE, Familian A, van Mierlo GJ, Dijkmans BAC, Hack CE. Complement activation in patients with rheumatoid arthritis mediated in part by C-reactive protein. Arthritis Rheum 2001;44:997-1002.

\section{$\mathrm{ECHO}$}

\section{Acute panuveitis in a child with Takayasu's arteritis}

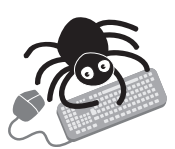

Please visit the Annals of the Rheumatic Diseases website [www. annrheumdis. com] for a link to the full text of this article.
$\mathrm{T}$ akayasu's arteritis is a panarteritis involving the intima, media, and adventitia of the larger vessels of the neck, thorax, and abdomen. It is most common in southeast Asia, affects women more than men, and rarely affects children. It may cause ischaemic optic neuropathy but has rarely been associated with inflammatory eye disease. A boy in Australia developed acute panuveitis with Takayasu's arteritis.

At presentation the 12 year old boy, who was of Chinese origin, had a two day history of low grade fever, occipital headache, nausea, and vomiting. His blood pressure was 180/ $110 \mathrm{~mm} \mathrm{Hg}$ and temperature $39.9^{\circ} \mathrm{C}$ but he otherwise appeared well and fundoscopy and visual acuity were normal. Erythrocyte sedimentation rate was $93 \mathrm{~mm} / \mathrm{hour}$ and serum creatinine $85 \mu \mathrm{mol} / \mathrm{l}$. His hypertension was controlled with four drugs. Renal Doppler ultrasound and magnetic resonance angiography (MRA) of neck, chest, and abdomen indicated bilateral renal artery stenosis but no other vascular abnormality. Renal angiography confirmed severe stenosis of only the left renal artery and his hypertension resolved after balloon angioplasty. He subsequently developed bilateral anterior uveitis and was treated with steroid eye drops and cycloplegics. Two months later he developed panuveitis and upper limb and carotid pulses were weak. MRA showed severe stenosis of the origin of the left vertebral artery and both subclavian arteries. A diagnosis of Takayasu's arteritis was made and he was given intravenous methylprednisolone followed by eight weeks of oral prednisolone, cyclophosphamide, and aspirin and then maintenance treatment with methotrexate and low dose prednisolone. He developed chronic uveitis in the left eye but remained normotensive and the arterial stenoses improved.

This case is unique in that there was panuveitis without glaucomatous ischaemic changes and with negative antineutrophil cytoplasmic antibody (ANCA) tests and no evidence of sarcoidosis, Wegener's granulomatosis, or Cogan's disease.

A Archives of Disease in Childhood 2003;88:938-939. 